\title{
Henri Lancelot Voisin de La Popelinière, Du «Contre Machiavel» au «Contre-Prince de Machiavel»
}

\section{Michele Mastroianni}

\section{(2) OpenEdition}

1 Journals

\section{Edizione digitale}

URL: http://journals.openedition.org/studifrancesi/5912

DOI: 10.4000/studifrancesi.5912

ISSN: 2421-5856

\section{Editore}

Rosenberg \& Sellier

\section{Edizione cartacea}

Data di pubblicazione: 1 mai 2011

Paginazione: 159

ISSN: 0039-2944

\section{Notizia bibliografica digitale}

Michele Mastroianni, «Henri Lancelot Voisin de La Popelinière, Du «Contre Machiavel» au «Contre-Prince de Machiave/»», Studi Francesi [Online], 163 (LV | I) | 2011, online dal 30 novembre 2015, consultato il 13 janvier 2021. URL: http://journals.openedition.org/studifrancesi/5912 ; DOI: https://doi.org/10.4000/ studifrancesi.5912

Questo documento è stato generato automaticamente il 13 janvier 2021.

\section{(c)}

Studi Francesi è distribuita con Licenza Creative Commons Attribuzione - Non commerciale - Non opere derivate 4.0 Internazionale. 


\title{
Henri Lancelot Voisin de La Popelinière, $\mathrm{Du}$ «Contre Machiavel» au «Contre-Prince de Machiavel»
}

\author{
Michele Mastroianni
}

\section{NOTIZIA}

HENRI LANCELOT VOISIN DE LA POPELINIÈRE, Du «Contre Machiavel» au «Contre-Prince de Machiavel», édition établie et annotée par Brigitte Lourde, Genève, Droz, 2010 («Les classiques de la pensée politique», 22), pp. 147.

1 La Popelinière aveva consacrato cinque testi, rimasti a tutt'oggi inediti (e poco conosciuti dalla critica), a Machiavelli, o meglio alla polemica contro il machiavellismo. Nel ms. BN, fr. 20787 abbiamo il primo (titolo: Le Contre-Machiavel), nel ms BN, fr. 20797 abbiamo gli altri quattro titoli: 1) Pourquoy les Chrestiens ny autres peuples de ce tems n'ont peu et ne peuvent representer les Grans faits des anciens contre Machiavel qui en fait cause la Religion Chretiene; 2) Le Contre-Prince de Machiavel; 3) Le Contre-Machiavel; 4) Le ContreMachiavel). Sempre il ms. BN, fr. 20797 contiene un altro interessante inedito di La Popelinière, la Responce pour l'Histoire, un discorso pronunciato dall'autore nel 1585, contro gli attacchi dei correligionari protestanti alla sua Histoire de France. Ora, questi sei testi vengono pubblicati in edizione critica, con un'accurata introduzione storico filologica. I trattatelli antimachiavellici si inseriscono nella polemica aperta da Gentillet, ma sono più tardivi: la datazione, ipotetica ma probabile, proposta dalla curatrice è il decennio 1599-1608. Nell'introduzione un utile paragrafo è consacrato alla ricostruzione dei possibili canali di accesso all'opera di Machiavelli da parte di La Popelinière, con annotazioni che servono alla storia della fortuna francese dell'autore del Principe. Interessanti anche sono le considerazioni sull'antimachiavellismo di La Popelinière, che dimostra un atteggiamento fortemente critico nei confronti dell'AntiMachiavel di Gentillet-e delle argomentazioni protestanti in genere su questo soggetto - in quanto alle obiezioni di carattere morale e religioso nei confronti del 
pensiero di Machiavelli unisce un riconoscimento del valore dello storico fiorentino, qualificato «homme judicieux et qui a bien remarqué». 